\title{
Duplicate vas deferens in a 3-year-old boy: a case report and review of paediatric literature
}

\author{
Justina O. Seyi-Olajide ${ }^{{ }^{*}}$ (iD and Emmanuel A. Ameh²
}

\begin{abstract}
Background: Congenital abnormalities of the vas deferens are very uncommon. Duplicate vas deferens is a rare abnormality. It is the presence of two separate vasa deferentia within one spermatic cord. It has been encountered during inguinal hernia repair, orchidopexy, varicocoelectomy, vasectomy and radical prostatectomy. Identification of the vas deferens is mandatory during surgeries involving manipulation of the spermatic cord because if duplication exists and is not detected, there is increased chance of iatrogenic injury.

Case presentation: We present a 3-year-old boy with duplicate vas deferens identified during herniotomy for a right hydrocele. A postoperative abdominopelvic ultrasound scan revealed no abnormalities.

Conclusion: The risk of iatrogenic injury to the vas is increased in the presence of a duplication. A deliberate identification of the vas during procedures involving manipulation of the spermatic cord reduces this risk.
\end{abstract}

Keywords: Duplicate, Vas deferens, Herniotomy, Spermatic cord

\section{Background}

Congenital abnormalities of the vas deferens are very uncommon [1]. Duplicate vas deferens is a rare abnormality. It is the presence of two separate vasa deferentia within one spermatic cord and is rarely reported in literature worldwide [2] [3]. It has been encountered during inguinal hernia repair, orchidopexy, varicocoelectomy, vasectomy and radical prostatectomy [4]. A large number of inguinal surgeries in children are performed annually with attendant risk of injury to the vas deferens. The aim of this report is to raise awareness to this condition to minimize the potential risk of injury. The literature is also reviewed.

\section{Case presentation}

A 3-year-old boy presented with a 1-year history of painless right scrotal swelling. He had no other symptoms. Examination revealed a large irreducible right scrotal swelling which transilluminates brilliantly with the testis not separately palpable. A diagnosis of right hydrocele

\footnotetext{
* Correspondence: justinaseyiolajide@yahoo.com

${ }^{1}$ Paediatric Surgery Unit, Department of Surgery, Lagos University Teaching

Hospital, Idi-Araba, Lagos, Nigeria

Full list of author information is available at the end of the article
}

was made and he subsequently had a right herniotomy via an inferior groin crease incision. Intraoperative findings were a patent processus vaginalis and a fluid-filled tunica vaginalis. During separation of the processus vaginalis from the other contents of the spermatic cord, two separate similar-sized vas deferens were isolated (Fig. 1).

High ligation and division of the patent processus vaginalis was done, taking care to avoid injury to any of the cord structures. Intraoperative examination of the scrotum revealed a single testis and epididymis. The procedure was well tolerated and there were no postoperative complications. The patient subsequently had an abdominopelvic ultrasound scan which revealed no abnormalities.

\section{Discussion}

Anomalies of the vas deferens are rare with an estimated overall incidence of less than $0.05 \%$ in the general population. These may present as absence, ectopia, hypoplasia, diverticulum and duplication [5, 6]. Duplications are rare and only few cases have been reported in literature. It may be, however, that the estimated incidence is under-reported and the anomaly under-recognized [7]. A review of literature from 1948 till date showed that only 33 cases have been reported worldwide [1-31]. Of 


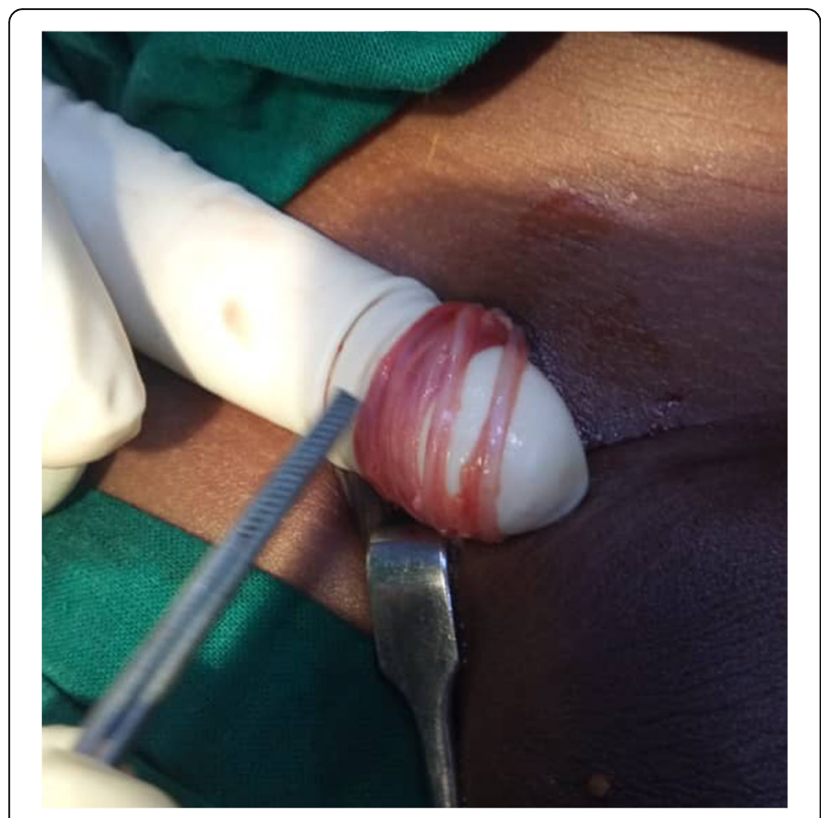

Fig. 1 Duplicate vas deferens during right herniotomy

these, only 9 cases were documented to have been detected in the paediatric age group. Our report is the 10th documented case in children. Duplicate vas is encountered usually during surgical procedures that involve inguinal exploration. Of the cases detected in children, 6 were discovered during orchidopexy, 2 during inguinal herniotomy and 1 during exploration for suspected right ectopic ureter (Table 1). The ages at surgery ranged between 7 months and 15 years and 7 of the patients had bilateral exploration. Of the 7 patients who had bilateral exploration, 5 had bilateral duplications of the vas deferens. Two of the surgeries were complicated by transection of the vas deferens, 2 patients had crossed testicular ectopia, 1 patient had ipsilateral renal agenesis and 2 patients were not evaluated for associated anomalies (Table 1).

Where available, intraoperative Doppler can help differentiate between the vas deferens and a vascular structure [7]. Previous reports have shown association between duplicate vas deferens and cystic fibrosis, unilateral renal agenesis and other renal anomalies [1] [3] [8].

Abdominopelvic ultrasound scan in the index patient demonstrated no abnormalities.

The embryogenesis of this anomaly is unclear. The vas deferens originates from the proximal vas precursor which is the central part of the mesonephric duct. Duplication of the fetal mesonephric ducts possibly gives rise to duplication of the vas deferens, while duplication of the proximal vas precursor presumably gives rise to partial duplication of the vas deferens at the level of the inguinal canal [5]/ Liang et al. proposed a classification system for the poly-vasa deferentia [4]. Type I describes duplicated vas deferens in the spermatic cord with no polyorchidism. Type II refers to multiple vas deferens with polyorchidism. Type III is a false poly-vasa deferentia where an ectopic ureter drains into the ejaculatory system. Based on this classification, the index patient had a Type I poly-vasa deferentia.

Due to the rarity of this condition, inadvertent injury of the vas deferens during surgeries involving exploration of the spermatic cord may occur $[1,15,26]$.

Conclusion A deliberate identification of the vas deferens is compulsory during surgeries involving manipulation of the spermatic cord in order to avoid injury. If duplication of the vas deferens exists and this is not detected, the chance of iatrogenic injury is increased. It is

Table 1 Reports of duplications of the vas deferens in children

\begin{tabular}{|c|c|c|c|c|c|c|c|}
\hline Author & Year & $\begin{array}{l}\text { Age in } \\
\text { years }\end{array}$ & Procedure & Complication & Associated anomalies & Side & $\begin{array}{l}\text { Bilateral } \\
\text { exploration }\end{array}$ \\
\hline This report & 2019 & 3 & Inguinal herniotomy & None & None on US & Right & No \\
\hline Karaman & 2010 & 1 & Orchidopexy & None & None on US & Left & Yes \\
\hline Kutiyanawala & 1998 & 3 & Bilateral orchidopexy & None & None on US & Bilateral & Yes \\
\hline Mege & 1997 & 4 & Orchidopexy & None & Not evaluated & Bilateral & Yes \\
\hline Mege & 1997 & 4 & Orchidopexy & None & Not evaluated & Left & Yes \\
\hline Barrack & 1994 & 10 months & Orchidopexy & None & Crossed testicular ectopia & Bilateral & Yes \\
\hline Binderow & 1993 & 2 & Inguinal herniotomy & Transected & None on US and IVP & Left & No \\
\hline $\begin{array}{l}\text { Tolete- } \\
\text { Velcek }\end{array}$ & 1988 & 10 & Orchidopexy & None & $\begin{array}{l}\text { Crossed testicular ectopia on } \\
\text { US }\end{array}$ & Bilateral & Yes \\
\hline $\begin{array}{l}\text { Tolete- } \\
\text { Velcek }\end{array}$ & 1988 & 7 months & Inguinal herniotomy & Transected & None on US & Bilateral & Yes \\
\hline Koyanagi & 1972 & 15 & $\begin{array}{l}\text { Exploration for suspected right ectopic } \\
\text { ureter }\end{array}$ & $\mathrm{Nil}$ & Ipsilateral renal agenesis & right & No \\
\hline
\end{tabular}


also important that surgeons carrying out these surgeries are aware of the existence of this anomaly.

\section{Acknowledgements}

Not applicable

\section{Authors' contributions}

JOS and EAA both contributed to the conception, drafting and revision of this work and approved the submitted version.

\section{Funding}

No funding was received for this manuscript.

\section{Availability of data and materials}

Available upon Request.

\section{Ethics approval and consent to participate}

Written informed consent to participate was obtained from the patient.

\section{Consent for publication}

Written consent for publication was obtained from the parent.

\section{Competing interests}

The authors declare that they have no competing interests.

\section{Author details}

${ }^{1}$ Paediatric Surgery Unit, Department of Surgery, Lagos University Teaching Hospital, Idi-Araba, Lagos, Nigeria. ${ }^{2}$ Division of Paediatric Surgery, National Hospital, Abuja, Nigeria.

Received: 18 October 2019 Accepted: 12 February 2020

Published online: 28 February 2020

\section{References}

1. Binderow SR, Shah KD, Dolgin SE. True duplication of the vas deferens. J Pediatr Surg. 1993;28(2):269-70

2. Breitinger MC, Roszkowski EH, Bauermeister AJ et al. Duplicate vas deferens encountered during inguinal hernia repair: a case report and literature review [Internet]. Case Reports in Surgery. 2016 [cited 2019 Feb 14]. Available from: https://www.hindawi.com/journals/cris/2016/8324925/.

3. Chintamani, Khandelwal $\mathrm{R}$, Tandon $\mathrm{M}$, et al. Isolated unilateral duplication of vas deferens, a surgical enigma: a case report and review of the literature. Cases J. 2009;2:167.

4. Liang MK, Subramanian A, Weedin J, et al. True duplication of the vas deferens: a case report and review of literature. Int Urol Nephrol. 2012;44(2): 385-91.

5. Damle S, Cothren CC, Moore EE, et al. Double trouble: duplication of vas deferens encountered during inguinal hernia repair. J Am Coll Surg. 2005; 201(1):141.

6. Akay F, Atug F, Turkeri L. Partial duplication of the vas deferens at the level of inguinal canal. Int J Urol. 2005;12(8):773-5.

7. Lee JN, Kim BS, Kim HT, et al. A case of duplicated vas deferens found incidentally during varicocelectomy. World J Mens Health. 2013;31(3):268.

8. Cetti R, Reuther K, Hansen JP. Double vas deferens. Ugeskr Laeger. 1980; 143(1):28.

9. Coetzee T. Double vas deferens: a case report. Br J Urol. 1959;31(3):336-9.

10. Erdemir F, Parlaktas BS, Yasar A, et al. Duplicated vas deferens: a rare congenital abnormality. Kaohsiung J Med Sci. 2008;24(4):210-1.

11. Gravesen RG. Double conjoining vas deferens. Urology. 1980;15(3):283-4.

12. Gravgaard E, Garsdal L, Møller SH. Double vas deferens and epididymis associated with ipsilateral renal agenesis simulating ectopic ureter opening into the seminal vesicle. Scand J Urol Nephrol. 1978;12(1):85-7.

13. Hjarbaek J. Double vas deferens. Ugeskr Laeger. 1987;149(32):2154-5.

14. Hublet D, Kaeckenbeeck B, De Backer E. Dysgenetic prostatic cyst and bilateral duplication of seminal vesicles with unilateral duplication of vas deferens, epididymis and renal dysplasia. One case and review of the literature. Acta Urol Belg. 1980;48(3):424

15. Karaman A, Karaman I, Yagiz B, et al. Partial duplication of vas deferens: How important is it? J Indian Assoc Pediatr Surg. 2010;15(4):135.

16. Khandelwal R, Punia S, Vashistha N, et al. Duplication of vas deferens-a rare anomaly with review of literature. Int J Surg Case Rep. 2011;2(8):241-2.
17. Koyanagi T, Tsuji I, Kudo T, et al. Double vas deferens associated with psilateral renal agenesis, simulating ectopic ureter. J Urol. 1972;108(4):631-4.

18. Kutiyanawala MA, Johnstone JM. A double vas deferens. Br J Urol. 1998; 81(4):647.

19. Mathé CP, Dunn G. Double vas deferens associated with solitary kidney: cse report 1. J Urol [Internet]. 1948 Mar [cited 2019 May 23]; Available from: https://www.auajournals.org/doi/abs/10.1016/S0022-5347\%2817\%2969398-4

20. Mege J-L, Sabatier-Laval E, Mure P-Y, et al. Malformations of Wolffian duct derived male genital organs (epididymis, vas deferens, seminal vesicules, ejaculatory ducts). Progres En Urol J Assoc Francaise Urol Soc Francaise Urol. 1997;7(2):262-9.

21. Mysorekar VR. Accessory vas deferens: a case report. Br J Urol. 1976;48(1):82.

22. Saadeldin OA, Abd El Salam MA, Azzazi OA, et al. A rare case of duplicated vas deferens discovered accidentally during varicocelectomy. Andrologia. 2018 Nov:50(9):e13108.

23. Shariat SF, Naderi ASA, Miles B, et al. Anomalies of the Wolffian duct derivatives encountered at radical prostatectomy. Rev Urol. 2005;7(2):75-80.

24. Sirasanagandla SR, Nayak SB, Jetti R, et al. Unilateral duplication of vas deferens: a cadaveric case report. Anat Cell Biol. 2013 Mar;46(1):79-81.

25. Terawaki K, Satake $\mathrm{R}$, Takano N, et al. A rare case of duplicated vas deferens and epididymis. J Pediatr Surg Case Rep. 2014;2(12):541-3.

26. Tolete-Velcek F, Leddomado $E$, Hansbrough F, et al. Alleged resection of the vas deferens: medicolegal implications. J Pediatr Surg. 1988 Jan;23(1):21-3.

27. Tolete-Velcek F, Bernstein MO, Hansbrough F. Crossed testicular ectopia with bilateral duplication of the vasa deferentia: an unusual finding in cryptorchism. J Pediatr Surg. 1988 Jul 1;23(7):641-3.

28. Barrack S. Crossed testicular ectopia with fused bilateral duplication of the vasa deferential: an unusual finding in cryptochidism. East Afr Med J. 1994; 71(6):398-400

29. Carr R. Apparent bilateral duplication of the vas deferens. Br J Urol. 1993; 71(3):354-60.

30. Khaliq T, Malik ZI, Jamal SI. True duplication of the vas deferens. J Pak Med Assoc. 1997:47(3):97-8

31. Khoudary KP, Morgentaler A. Partial duplication of the vas deferens. J Urol. 1998:159(3):988-9.

\section{Publisher's Note}

Springer Nature remains neutral with regard to jurisdictional claims in published maps and institutional affiliations.

\section{Submit your manuscript to a SpringerOpen ${ }^{\circ}$ journal and benefit from:}

- Convenient online submission

- Rigorous peer review

- Open access: articles freely available online

High visibility within the field

Retaining the copyright to your article

Submit your next manuscript at $>$ springeropen.com 